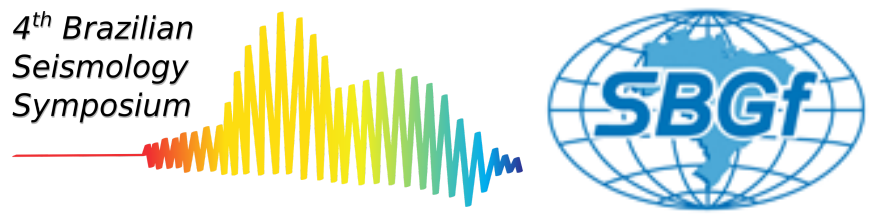

\title{
Multi-Frequency tomography using absolute travel times of P-waves and S-waves to constrain the mantle velocity structure beneath southeastern South America
}

\author{
Lais N. Rodrigues ${ }^{1}$, Carlos A. M. Chaves ${ }^{1}$, Fabio L. Dias ${ }^{2}$, Sergio L. Fontes ${ }^{2}$, Marco A. T. Romeiro ${ }^{3}$, \\ ${ }^{1}$ Universidade de São Paulo, ${ }^{2}$ Observatório Nacional, ${ }^{3}$ Petrobras \\ Copyright 2021, SBGf - Sociedade Brasileira de Geofísica. \\ This paper was prepared for presentation during the $17^{\text {th }}$ International Congress of the Brazilian Geophysical Society held in Rio de Janeiro, Brazil, 8-11 November 2021 (Online Event). \\ Contents of this paper were reviewed by the Technical Committee of the $17^{\text {th }}$ International Congress of the Brazilian Geophysical Society and do not necessarily represent any position of \\ the SBGf, its officers or members. Electronic reproduction or storage of any part of this paper for commercial purposes without the written consent of the Brazilian Geophysical Society is \\ prohibited.
}

\begin{abstract}
In this study, we present new velocity models of P-waves and S-waves for the mantle beneath southeastern South America using multi-frequency seismic tomography. Southeastern South America encompasses important magmatic provinces (e.g., Paraná Magmatic Province, Serra do Mar and Goiás Alkaline Provinces) and tectonic structures (e.g., Paraná Basin, São Francisco Craton, Ribeira Belt) whose origin and evolution are still under investigation. From the analysis of vertical, transversal and radial seismograms recorded by seismic stations in South America, in the period between 1992 and 2020, we estimate travel times residuals for P-waves (e.g, P, PKIKP, PcP) and S-waves (e.g., S, SKS, ScS) by cross-correlating synthetic and recorded seismograms. Synthetic seismograms are calculated using the 1D velocity structure from the AK135 model and moment tensors from the GCMT catalog. Measurements are performed on bandpass-filtered seismograms for six different periods: $50 \mathrm{~s}, 32 \mathrm{~s}, 20 \mathrm{~s}, 16 \mathrm{~s}, 10 \mathrm{~s}$ and $6 \mathrm{~s}$ for multi-frequency imaging. Ellipticity, crustal velocity structure and station elevation corrections are applied to our measured travel times residuals. For the modeling of our travel time dataset, finite-frequency sensitivity kernels are estimated from an efficient method, which uses ray theory, Born and paraxial approximations to obtain the first Fresnel zones around the geometrical path of the seismic ray. We combine high-frequency travel times anomalies from the ISC-EHB bulletin with our measurements for improving the resolution of our models. This adds more than one million P-waves and $S$-waves travel times residuals to our database. We invert our combined dataset of travel time anomalies using the LSQR method to obtain a new image of the mantle heterogeneous velocity structure under southeastern South America. To assess the resolution of the estimated velocity models, we perform the traditional checkerboard test, which shows that our dataset may resolve structures with a wavelength larger than $250 \mathrm{~km}$, starting at crustal depths of about $30 \mathrm{~km}$. So far, for lithospheric depths, this is an unprecedented resolution obtained from body-wave tomography experiments in southeastern South America. Our preliminary P-wave model shows high-velocity anomalies extending from the depth of $30 \mathrm{~km}$ to the depth of $200 \mathrm{~km}$ that support the idea of a fragmented lithosphere under the Paraná Basin. A strong low-velocity anomaly of about $2 \%$ is recovered beneath the central part of the Chaco-Paraná basin, starting at a depth of $100 \mathrm{~km}$ and going towards the south of the basin to a depth of $300 \mathrm{~km}$. High P-velocity perturbations are observed along the Brazilian continental margin from a depth of $30 \mathrm{~km}$ to $130 \mathrm{~km}$ and from then on, we observe low-velocity perturbations. Additional observed anomalous features are still being interpreted and will be presented along with possible geodynamic scenarios, which might have originated and influenced the tectonic evolution of this region.
\end{abstract}

